\title{
Do "trainee-centered ward rounds" help overcome barriers to learning and improve the learning satisfaction of junior doctors in the workplace?
}

\author{
This article was published in the following Dove Press journal: \\ Advances in Medical Education and Practice \\ 13 October 2015 \\ Number of times this article has been viewed
}

\author{
Vikas Acharya' \\ Amir Reyahi ${ }^{2}$ \\ Samuel M Amis ${ }^{3}$ \\ Sami Mansour ${ }^{2}$ \\ 'Department of Neurosurgery, \\ University Hospitals Coventry and \\ Warwickshire, Coventry, ${ }^{2}$ Luton and \\ Dunstable University Hospital, Luton, \\ ${ }^{3}$ Warwick Medical School, University \\ of Warwick, Coventry, UK
}

\begin{abstract}
Ward rounds are widely considered an underutilized resource with regard to medical education, and therefore, a project was undertaken to assess if the initiation of "trainee-centered ward rounds" would help improve the confidence, knowledge acquisition, and workplace satisfaction of junior doctors in the clinical environment. Data were collated from junior doctors, registrar grade doctors, and consultants working in the delivery suite at Luton and Dunstable University Hospital in Luton over a 4-week period in March-April 2013. A review of the relevant literature was also undertaken. This pilot study found that despite the reservations around time constraints held by both junior and senior clinicians alike, feedback following the intervention was largely positive. The junior doctors enjoyed having a defined role and responsibility during the ward round and felt they benefited from their senior colleagues' feedback. Both seniors and junior colleagues agreed that discussing learning objectives prior to commencing the round was beneficial and made the round more learner-orientated; this enabled maximal learner-focused outcomes to be addressed and met. The juniors were generally encouraged to participate more during the round and the consultants endeavored to narrate their decision-making, both were measures that led to greater satisfaction of both parties. This was in keeping with the concept of "Legitimate peripheral participation" as described by Lave and Wenger. Overall, trainee-centered ward rounds did appear to be effective in overcoming some of the traditional barriers to teaching in the ward environment, although further work to formalize and quantify these findings, as well as using greater sample sizes from different hospital departments and the inclusion of a control group, is needed.
\end{abstract}

Keywords: medical education, learner-focused ward rounds, trainee-centered ward round, workplace-based learning

\section{Introduction}

Most clinicians either reflecting on their present training, if still ongoing, or contemplating their previous time as a junior doctor, if now historical, can appreciate that considerable obstacles to learning exist in the ward environment. High volumes of patients, untimely medical emergencies, and ongoing increases in administrative tasks make it difficult to allocate time for learning or, in some instances, actually have a positive educational experience at all. In fact, many junior doctors perceive the rotations of their foundation years as a "survival exercise". ${ }^{1}$ Despite these obstacles, the ward is still an invaluable asset where the majority of junior doctors' learning needs happen to help increase their competence and improve their confidence. The humble ward round represents a prime
Department of Neurosurgery, University Hospitals Coventry and Warwickshire, Clifford Bridge Road, Coventry, CV2 2DX, UK

Tel +442476964000

Email vikas.acharya@doctors.org.uk 
example of a regularly wasted opportunity for learning. Junior doctors want to learn, senior clinicians (more than not) want to teach, and a busy department with high turnover of patients means there are ample opportunities for learning and teaching to take place; however, in reality, it rarely consistently does.

An underlying principle behind the concept of traineecentered ward is "legitimate peripheral participation". This term was coined by Lave and Wenger who argued that when a "community of practice" is first joined, such as a new consultant's firm, those individuals need to be allowed to contribute in a meaningful way from the beginning; even if initially these tasks are not as central to the function of the group. ${ }^{17}$ Over time, the trainees learn more effectively from participating in this "community of practice" and move from peripheral participation to full participation as confidence and competence grows. Ward rounds are an ideal opportunity for junior doctors to achieve this process of continuous deepening of participation. The senior-junior relationship can become more akin to an apprenticeship, and the satisfaction of both parties can be greatly enhanced.

\section{Ward rounds in the literature}

The fundamental importance of ward rounds and their place as an essential activity for doctors in hospital settings is self-evident. Clinicians use the ward round not only to set the working day and monitor patient progress, but also to assess new patients from diagnoses, and thus develop clinical management plans. Academics have formed a clear consensus that ward rounds are an ideal platform for workplace-based teaching and learning to occur. However, there has been considerable debate regarding how the educational value of ward rounds can be improved. For example, a clear disjunction exists between the teaching favored by senior doctors and the learning valued by their trainees. Consultants were of the opinion that their job was not imparting medical content knowledge on rounds, but rather that they were role-modeling particular skills, attitudes, and behaviors. The study by Kuper et al in 2010 found that trainees primarily wanted to learn content knowledge and that most of them did not value the role-modeling system as much as they valued the acquisition of this knowledge. ${ }^{2}$ Clearly, there is a divergence of opinion between trainer and trainee that needs to be bridged.

Walton and Steinert assert that ward rounds are an opportunity for powerful workplace-based learning but state their educational impact needs improvement. ${ }^{3}$ They list two concrete suggestions that can aid development including 1) ward rounds should be facilitated so that as many group members are as actively involved as possible, while being sufficiently controlled to ensure that teaching points are clearly made; 2) whenever possible, the order of patient discussion should be preplanned so that important clinical issues and specific teaching points are addressed earlier in the rounds, before time pressures take over.

The focus on structure was taken up earlier by Stanley in 1998. He considered the situations required to maximize learning on ward rounds. ${ }^{4}$ Stanley emphasized the value of structuring discussion time into rounds, in a place out of the hearing of patients and relatives so that trainers and trainees could take full advantage of opportunities to impart knowledge and discuss prevalent issues in a full and frank manner. Creating such situations leads to an open exchange of ideas, and Bhangu and Hartshorne took this idea up in 2011 when discussing the merits of consultant-led post-take ward rounds (PTWRs). ${ }^{5}$ PTWRs can be a particularly useful learning opportunity for junior doctors as the initial diagnoses given on admission by them/their colleagues can be revised and changed as necessary by the consultant. The juniors can also volunteer a full management plan, with the added benefit of being physically present right at the beginning of the patient's admission journey, for feedback. The authors were able to succinctly show why PTWRs are so important to a junior doctor's development. If the diagnosis is changed on the PTWR, it helps engender their own improvement in an appropriately safe environment without compromising patient care, which, of course, is the most important factor on whether an intervention is practicable.

As the daily workload varies by the hour, the workplace cannot and does not always offer the same learning opportunities to all learners. ${ }^{6}$ If this is the case, there needs to be a method of appreciating and encouraging the learning process for junior doctors so that opportunities that do arise are maximized and a consistent and fair environment exists. High-quality learning can arise simply from engagement in the workplace but from our experience, this works better and more consistently with active encouragement from seniors. If participation in workplace activities is the only avenue for learning, then this can be highly variable; it is very dependent on the motivation of the trainee and equally, the enthusiasm of the trainer. There are simple measures that form our "trainee-centered ward rounds", which we believe can help overcome barriers to learning on ward rounds but not necessarily entail a rigid structural framework.

\section{Our trainee-centered ward rounds}

Traditional ward rounds in the UK usually involve a consultantled review of the patient's diagnosis and management plan with 
junior doctors (usually FY1/FY2 - intern equivalent in the USA) aiding this process by documenting in the notes, relaying recent investigations and collateral information/resources to the consultant, as well as carrying out clerical and clinical jobs that come from the round such as discharge summaries and relevant tests. This traditional practice often does not include many occasions for direct learning from their seniors due to workload pressures; many consultants view their teaching role to the junior as one simply of observation.

Junior and senior doctors both understand and appreciate the importance of overcoming barriers to learning and enhancing learning experiences for junior doctors, especially by making junior doctors feel more integrated with team members and giving them ownership and responsibility for patient care. One of the ways that this can be achieved as part of traineecentered ward rounds is for the senior clinician to assign the juniors a patient to assess while the consultant sees someone else. The junior doctor can then present the patient back to the consultant and receive feedback on their assessment and management plan. Usually, junior doctors are required by the consultant to carry out clerical roles during the ward round as mentioned above; thus, there is little opportunity for them to assess a patient themselves. Another facet of trainee-centered ward rounds is encouraging the senior clinician to speak their thoughts aloud and thereby allow the juniors to learn from their decision-making process. Furthermore, the consultants were encouraged to explicitly allow time for questions to be asked and to check understanding intermittently, and the junior doctors were similarly encouraged to ask more questions as they came up. Finally, the trainee-centered ward rounds involved a brief discussion, prior to commencing the round, regarding what objectives the trainees wanted to focus on, and the round would then be tailored as appropriate to their learning needs and requirements.

\section{Materials and methods}

A prospective cohort observational study was undertaken in the delivery suite at the Luton and Dunstable University Hospital in Luton, UK. It was longitudinal in nature as it followed the same group of people over a period of 4 weeks on a weekly basis. The research/data sample was from clinicians working in the delivery suite during March-April 2013. The participants consisted of six junior doctors (FY1/FY2/ST1 level), six registrar grade doctors, and six consultants in obstetrics and gynecology. Verbal feedback was received after informal interventions with the various participants and formed part of the ethnographic data collection prior to the intervention. A faculty debriefing session after the trial period had ended was also used to assess the impact of the trainee-centered ward rounds retrospectively in addition to the interviews with junior doctors and consultants prior to, during, and after the intervention.

It has been highlighted in various previous studies that using focus groups, participant observation, and ethnographic data have a strong value in accurate findings for educational development. ${ }^{7}$ This has been documented to be particularly important to enable one to gain an insider's narrative and observe practice and change as it happens. ${ }^{8}$ This was a crucial factor and requirement for us in our study. Being part of the actual team itself, we wanted to highlight the benefits for the department and maximize the benefits available and thus decided to use field observation study and focus groups/ discussions for our study. The informal discussions had salient notes documented with field notes, and the faculty debriefing session was recorded with consent for analysis and coding. Informed patient consent was not required for this study and patients were not involved in the research, however, consent was obtained from participants involved in the study including junior and senior doctors alike. This study was approved within the department but no formal hospital ethical approval was sought.

\section{Results}

The informal interviews and discussions prior to instigating learner-centered ward rounds found that both senior and junior doctors clearly felt that it would not be effective. Not only are their ward rounds rushed and busy, but senior clinicians do not take the time out to teach and junior doctors feel too busy and pressurized due to the workload to be able to even ask questions related to the clinical work let alone for teaching. "The bleep goes off every five minutes. We don't even have a chance to breathe let alone ask for teaching", said one junior. During the trainee-centered ward round month and on reflection afterward, junior doctors enjoyed being given responsibility of having their "own patient" during ward rounds. This allowed them to discuss the rationale for investigations/treatment and could receive "on the spot teaching and feedback related to cases". Junior doctors also felt they were learning "a lot more when senior clinicians involved them in decision-making related to patients on the ward round", and it provided ample opportunities to ask questions or clarify uncertainties. It also coincidentally facilitated workplace-based assessments to be regularly undertaken, an added benefit for the learners.

Both senior and junior doctors felt it was especially beneficial to ask the learners what they wanted to focus on or 
gain from the ward round prior to it starting. Junior doctors felt the round was then focused on them and gave them an opportunity to meet their learning needs. It encouraged and enabled juniors to undertake self-directed learning upon completion of the ward rounds to consolidate their learning and apply it to future clinical practice. Junior and senior doctors both felt "clinical priorities and patient care was more important than teaching during ward rounds"; therefore, with advice from us, senior clinicians were advised to "speak out loud" and explain their thought process when making decisions for acutely unwell patients if time could not be spared to have a formal discussion. This gave junior doctors new opportunistic learning that they enjoyed and made them use it in turn on a daily basis during ward rounds to describe, explain, and practice relevant narration back to senior colleagues. The faculty debrief also highlighted the "enjoyment of senior clinicians making ward rounds more interactive and junior doctor focused". It initially was felt that the learner-centered ward rounds would be very timeconsuming and inefficient. Upon completion, it was found that when junior doctors were given responsibility of one patient whilst the senior doctor reviewed another, both juniors and senior clinicians actually felt "it took no longer than previous", noneducationally focused ward rounds.

Junior doctors' job satisfaction is an important measure for assessing the success of interventions designed to improve learning in the workplace. This is dependent on many factors such as their rotation specialty, their colleagues, the learning experiences they encounter, and how welcomed they felt as part of a team. Prior to this project, junior doctors in this specialty overall felt minimally involved in clinical care delivery and thus felt they were not learning about this specialty. One junior doctor even quoted, "especially compared to midwives, they're always given priority". The consultants concurred with this during the faculty debrief, "midwives do prioritize other midwives or their students before thinking about junior doctors' learning". From the participant observation, it was found that junior doctors thrived when given responsibility. This made them feel more part of the team and value their role while satisfying their desire to treat patients and use their clinical skills rather than undertake mundane clerical tasks. It was also found that junior doctors were happier to undertake these clerical and administrative tasks when given other responsibilities as well. "I don't mind doing all the paperwork and tta's and bloods and stuff as long as it's not the sole purpose of my existence". Junior doctors also found it useful when they were given opportunistic learning during ward rounds; they found this to be very relevant to their daily practice for care delivery. This was also noted by senior clinicians in the faculty debrief: "I think they engaged with the process well and really enjoyed relevant learning opportunities".

This satisfied junior doctors from a learning experience and job satisfaction point of view. They correlated this learning with them being able to apply it to future clinical practice to improve the care they provide to patients. From the faculty debrief, the findings highlighted that senior clinicians enjoyed the experience of teaching junior doctors in the clinical setting. They believed that it not only fulfilled their duty as a senior, but also gave them the feeling that the juniors were more likely to be safer and competent practitioners having gained this knowledge. "It was nice to see the old tradition of apprentice and teacher back in action, where the juniors actually were interested and saw the importance of the teaching in order to affect clinical practice. I thoroughly enjoyed it". As junior doctors gained confidence and became more integrated, seniors felt they trusted and respected the junior doctors increasingly and saw them more as core team members.

\section{Discussion}

The findings of this project highlighted that prior to any trial interventions, junior and senior doctors had different views on whether the trainee-centered ward rounds would work. This is an important finding that has been documented in various studies, including the one by Kuper et al in 2010, where the difference in learners' and teachers' expectations from what can be gained from ward rounds was extensive. ${ }^{2}$ Junior doctors felt that they were under too much pressure in the demanding workplace and would not be able to turn them into teaching ward rounds. Senior clinicians, however, although agreeing with time restraints, overall thought differently. They felt it would provide good exposure to relevant and real clinical cases and learning opportunities. The literature suggests that ward rounds are a core part of a doctor's daily activity; therefore, it provides significant learning and teaching opportunities. ${ }^{9}$ Relating to educational and professional impact, it highlights the difference between seniors' and juniors' perceptions to learning opportunities, specifically if the learning is not made explicit. This will need to be considered for any future work taking place and for workplace learning enhancement.

During the project, junior doctors changed their views on the intervention and enjoyed the new focus and exposure, especially the teaching and feedback they received from senior colleagues. The fact that views and opinions were changed shows the potential benefit of this interven- 
tion; junior doctors did appear to have improved learning experiences and confidence levels. Even though time constraints were a concern prior to the intervention, in reality, the feedback obtained from this study suggested there was no perceived significant difference in ward round times. ${ }^{10}$ Having a junior doctor focused ward round enabled selfdirected learning and clarification afterward and consolidated the learning that was taking place. A study by Khan et al in 2011 supports this finding, where consultant feedback benefited their learning process. ${ }^{11}$ This finding is not uncommon among the ward-round literatures. Walton and Steinert also found this but mentioned that the educational impact it can have does require improvement ${ }^{3}$ and that feedback provided to juniors to regularly take place and be sustained.

\section{Limitations}

This study has a number of limitations, largely due to its purpose as a pilot study, which will hopefully lead on to further work in this field. The findings from anecdotal and ethnographic data need to be formalized and verified using standardized questionnaires, and there would also need to be a control group in future studies, which was lacking in this pilot. A number of factors, such as ward-round duration, junior and senior doctor satisfaction, junior doctor competency and clinical skills (from work-based assessment), as well as junior doctor confidence, could then be compared against this control group to more fairly assess any improvement caused by learner-centered ward rounds.

Additionally, supplementary investigations into whether or not trainee-centered ward rounds can help to improve junior doctor competency (ie, knowledge and clinical skills) in a measurable way, such as workplace-based assessments, would be vital in demonstrating their utility to senior clinicians. Similarly, one of the main findings of this pilot study was that from the perspective of the clinicians interviewed, the ward rounds were not appreciably longer in duration than they usually were. This is another finding that requires further investigation to actually time and quantify how long trainee-centered ward rounds take compared with their current/traditional ward rounds. One study that looked into ward-round duration, based on the review of 1,700 patients, found that routine rounds took on average 10 minutes per patient, while PTWRs took 14 minutes per patient. ${ }^{17}$ This could be used as a benchmark timeframe or current ward rounds can be timed in that specific unit.

Another issue to consider when interpreting the findings of this study is that any conclusions drawn may only be applicable to ward rounds on the delivery suite. Further work is necessary to investigate whether trainee-centered ward rounds would be useful or practicable in other specialties/ departments. Different specialties have different workforce pressures, for example, the recent reduction of FY1 numbers on surgical wards may exacerbate time constraints and make it more difficult for the junior to assess a patient individually before presenting back to seniors. Furthermore, the ward round forms a greater portion of the work done by the ward staff in other specialties such as internal/general medicine, where as in obstetrics or emergency medicine, it contributes significantly less to the proportion of the working day.

\section{Conclusion}

The involvement and participation of junior doctors is a significant factor associated with learning in the workplace. One must remember that "peripherality" is a way of learning that protects the individual by limiting exposures and experiences to what is relevant and appropriate at the time; however, during this specific, or other, rotations, it should be used in the positive way as described by Lave and Wenger so that one can become more integrated and involved. ${ }^{16}$ At present, junior doctors may not actively involve themselves in the workplace learning opportunities unless they are made explicit. In this project, these opportunities were highlighted and thus they were utilized. If they now become more engaged in the workplace and participate more actively, they will be able to learn and gain from the available learning opportunities. They are also increasingly likely to become a member of the community in which they are practicing and so could be described as moving from "legitimate peripheral participation to full engagement”. Evidence suggests that learners benefit from and enjoy patient interaction $;{ }^{14}$ it creates a positive learning environment and experience for learners, and this report also describes that as a key finding. ${ }^{15}$ Not only does it also increase participation but encourages them to become more part of this "community of practice". ${ }^{13}$

If this trial intervention is utilized by the faculty, this could have a beneficial impact on education and professionalism in the department both short and long term, particularly, if it is junior doctor led and driven but facilitated by senior clinicians. Having this intervention means the wider team are aware of the medical education topics, the evidence base that exists, and a platform for discussion and problem solving together as a team to enhance their workplace for learning made available. If this is continually undertaken and barriers are overcome, learning opportunities and learning experiences may improve and thus the feedback to governing bodies for the department potentially could change. ${ }^{12}$ The success of 
this intervention could see the formation of a "community of practice" not only for the faculty overseeing the work, but also for those involved at ground level. This will have a significant professional impact for the department not only from a hospital point of view, but as a specialty on a national basis. Pioneering this intervention and having it trainee-led gives ownership to the juniors to be involved in leading their own learning; this could be presented and modeled nationally to help improve applications to this less popular specialty as a career.

Trainee-centered ward rounds do appear to be effective in overcoming barriers to learning and did help improve learning opportunities, and thus satisfaction for junior doctors in a busy workplace. However, ward rounds consist of a series of complex tasks that require more than just medical knowledge, namely, interpersonal, clinical-technical, patient-management, and communication skills. ${ }^{13}$ A good structure can help maximize the learning that could take place during ward rounds. ${ }^{4}$ This can be done by overcoming these barriers to learning using the theories of "Legitimate peripheral participation" and encouraging junior doctors to join the "community of practice". Not only does it increase participation but encourages them to become more part of this "community of practice". ${ }^{17}$ They can then work alongside their colleagues as one, providing optimum patient care by learning from them, including through transfer of skills.

\section{Acknowledgments}

The authors would like to acknowledge and thank the staff involved in the project in the delivery suite and department of Obstetrics and Gynaecology at the Luton and Dunstable University Hospital.

\section{Disclosure}

The authors report no conflicts of interest in this work.

\section{References}

1. Bligh J. The first year of doctoring: still a survival exercise. Med Educ. 2007;36:2-3.

2. Kuper A, Nedden NZ, Etchells E, Shadowitz S, Reeves S. Teaching and learning in morbidity and mortality rounds: an ethnographic study. Med Educ. 2010;44:559-569.

3. Walton J, Steinert Y. Patterns of interaction during rounds: implications for work-based learning. Med Educ. 2010;44:550-558.

4. Stanley P. Structuring ward rounds for learning: can opportunities be created? Med Educ. 1998;32:239-243.

5. Bhangu A, Hartshorne G. Ward rounds: missed learning opportunities in diagnostic changes? Clin Teach. 2011;8:17-21.

6. Billett $\mathrm{S}$. Workplace pedagogic practices: co-participation and learning. Br J Educ Stud. 2002;50:457-481.

7. Atkinson P, Pugsley L. Making sense of ethnography and medical education. Med Educ. 2005;39:228-235.

8. Barbour R. Making sense of focus groups. Med Educ. 2005;39: 742751.

9. Norgaard K, Ringsted C, Dolmans D. Validation of a checklist to assess ward round performance in internal medicine'. Med Educ. 2004;38: 700-707.

10. Bradley P. The history of simulation in medical education and possible future directions. Med Educ. 2006;40:254-262.

11. Khan K, Pattison T, Sherwood M. Simulation in medical education. Med Teach. 2011;33:1-3.

12. Cook D, Bordage G, Schmidt H. Description, justification and clarification: a framework for classifying the purposes of research in medical education. Med Educ. 2008;42:128-133.

13. Nikendei C, Kraus B, Schrauth M, Briem S, Junger J. Ward rounds: how prepared are future doctors? Med Teach. 2008;30:88-91.

14. Swanwick T, Morris C. Shifting conceptions of learning in the workplace. Med Educ. 2010;44:538-539.

15. van Hell EA, Kuks JB, Cohen-Schotanus J. Time spent on clerkship activities by students in relation to their perceptions of learning environment quality. Med Educ. 2009;43:674-679.

16. Lave J, Wenger E. Situated Learning: Legitimate Peripheral Participation. Cambridge: Cambridge University Press; 1991.

17. Herring R, Desai T, Caldwell G. Quality and safety at the point of care: how long should a ward round take? Clin Med. 2011;11:20-22.
Advances in Medical Education and Practice

\section{Publish your work in this journal}

Advances in Medical Education and Practice is an international, peerreviewed, open access journal that aims to present and publish research on Medical Education covering medical, dental, nursing and allied health care professional education. The journal covers undergraduate education, postgraduate training and continuing medical education

\section{Dovepress}

including emerging trends and innovative models linking education, research, and health care services. The manuscript management system is completely online and includes a very quick and fair peer-review system. Visit http://www.dovepress.com/testimonials.php to read real quotes from published authors. 